\title{
ENVIRONMENTAL CHALLENGE AND CURRICULAR RESPONSES IN HONG KONG
}

Philip Stimpson The University of Hong Kong, Hong Kong

SUMMARY The paper discusses the changing perceptions of environmental problems and challenges in Hong Kong which have led to EE initiatives. It looks at recent curricular developments in EE and the degree to which they are supported by present practices in teacher education. In the face of considerable air and water pollution problems, the territory has shifted from a largely technocentric, engineering/environmental health approach to solving environmental problems to one which stresses community education as an additional linchpin. Central educational authorities have encouraged a largely cross-curricular programme of EE. However, despite the rhetoric of official guidelines, developments in the schools are fragmentary with a focus on knowledge acquisition. The situation in teacher education institutions to a large degree parallels that in the schools. The efficacy of teacher education in facilitating change is insufficient and is mainly attributable to the style of teacher education programmes in the territory.

\section{Introduction}

Hong Kong has struggled with developing environmental education (EE) within schools since the mid-1980s. Introducing EE has not been an easy process being constrained by inherent features within the educational system. Hong Kong's environment, as in many other 
industrialised and intensely urbanised areas, faces considerable stress. Environmental awareness expresses itself in Hong Kong as an odd mixture of extreme sensitivity and downright disregard. There are also parallels to this mixture in environmental education in schools where there is slippage between curriculum rhetoric of intent and classroom practice. Nevertheless, environmental education has started to make progress over the last five years or so. A rethinking and recasting of education in general, and EE in particular, is occurring; EE is becoming an accepted element of personal and social education. However, as with most curriculum implementation processes, rapid or radical change produces stress and there is a need to focus on catalysts and facilitators of the development process. Amongst environmental educators, not the least in Hong Kong, there is growing recognition that the training of teachers is a vital element for change if there are to be improvements in environmental education in schools (Tilbury, 1992; Wilkie 1985; UNESCO, 1980). Suitably educated personnel are crucial to the introduction of new environmental education programmes in the territory and the proper use of teaching materials. Teacher education is thus highlighted today as a 'priority of priorities' for overcoming curricular constraints.

This paper attempts to illuminate the development of EE in Hong Kong and the role of teacher education. It looks at three questions. What are the environmental problems and challenges that are faced in Hong Kong and that have led to EE initiatives? What developments have taken place in EE in the territory and with what success given the educational context? To what extent is teacher education supporting curricular initiatives in EE and what changes are needed in the ways teachers are educated?

\section{Environmental Challenge}


Underlying the nature of EE provision in any area are the perceptions of environment and environmental crisis held by the people who live there. Hong Kong is a cosmopolitan city, but at its roots it is a Chinese city. Thus, whilst account must be taken of Western perspectives towards the environment, Hong Kong exhibits a distinctively Chinese appreciation of the beauty of nature. This takes many forms from the delight of early morning walkers with their birds or the lady practising tai chi in the quiet leafy surroundings of an urban park to the formal chinese garden and the environmental implications of Feng Shui. In these senses, environment is part of a deep, highly personalised aesthetic experience.

In contrast, there is also considerable public, if not governmental, disregard for the environment particularly at the individual level. This disregard takes many forms, some related to personal life styles and others related to the urban-industrial function of Hong Kong. For example, international agreements concerning endangered species and habitat conservation receive little popular support. Consumerism and status as in the West are often stronger forces than environmentalism. Ivory goods can be, and still are, purchased. The attraction of certain chinese medicines are still a threat to some species. Compliance with agreements, such as CITES, is all too often superficial. There is a tendency towards "short-termism". Over the last two decades, the population has risen by $30 \%$ but GDP and the waste generation, which is linked to wealth creation, has increased by $300 \%$. Today, Hong Kong generates over 2 million tonnes of liquid wastes and 22,500 tonnes of solid and semisolid wastes per day. Concern for environmental quality at times often seems non-existent. The annual report of the environmental situation in Hong Kong (EPD, 1994), highlighted, amongst a number of concerns, the problem of illegal dumping of wastes by individuals. It is estimated that marine scavenging in the harbour 
yields 5,000 tonnes per annum not to mention the $0.2 \mathrm{~kg}$ of litter each visitor to a Country Park drops or the 3,000 tonnes of litter removed from beaches annually. The ability of the Hong Kong environment to assimilate these wastes is frequently exceeded. As a consequence, even in the open harbour, water quality does not attain acceptable levels and the median concentration of dissolved oxygen, a good indicator of water quality, being close to $50 \%$ saturation which is the minimum level that the water quality objectives allow. In 1989 and 1990, shell fish with paralytic poisoning toxins of 3 to 5 times the internationally recommended safety limits were found. The Environmental Protection Department (EPD) estimates that some 1.5 to two million people in a population of nearly six million are exposed to unacceptable levels of $\mathrm{SO}_{2}$ and $\mathrm{NO}_{2}$ and half the population suffers from high dust levels.

This schizophrenic attitude to the natural world and to people's surroundings (O'Riorden, 1989) is not unique to Hong Kong. Nonetheless, the gap between the actions of individuals and public statements of government's aims and intentions in the territory is at times great and as a consequence environment problems have become a matter of serious concern.

\section{Societal Responses to Environmental Problems}

If the nature of EE in Hong Kong is to be understood, it has to be seen in the context of general attitudes and approaches to solving environmental problems. Before the 1970s, environmental issues in Hong Kong were viewed, as in many other places, from a narrow perspective. There was an awareness about water quality problems from the 1950s, but this was essentially seen in a medical context of environmental health. As a consequence, action centred on pest control, street cleaning, refuse disposal, fish quality, etc. This was not unimportant for the well-being of society but it did not get to the heart of the matter treating the symptoms rather than the cause. 
The early 1970s marked a watershed as the environmental situation started to become markedly worse. The latter generated public recognition and the beginnings of action on a broader front than previously. In 1970, an Advisory Committee for resource development and nature conservation (EPCOM) was set up with a similar committee to consider the question of air pollution. A plan for a Country Parks programme was promulgated in 1972 in an effort to protect water catchments, conserve nature and provide leisure activities (Stimpson, 1985). The first park was designated in 1977 and there are now 21 parks covering $40 \%$ of the total land area. Mai Po marshes, a gei wai (shrimp pond) area in the north-west of the New Territories, came under official protection in 1973 following a suggestion in 1964 by the late Peter Scott of the World Wide Fund for Nature (WWF) that an educational nature reserve be set up. In 1978, Hong Kong adopted the concept of identifying and conserving sites of special ecological interest. Water Control Zones were instigated in the early 1980s and have had a major effect in reducing water pollution from animal waste (840,000 tonnes in 1987 to 360,000 tonnes in 1992).

To co-ordinate environmental initiatives, an Environmental Protection Unit was opened in 1978. Reflecting increased perceived importance, this became an Agency, the EPA, in 1981 with the job of formulating and executing government policy on the environment. It was reconstituted as a separate Government Department, the EPD, in 1986 with greater status and powers indicative of the new emphasis being put on the environment as both of the most recent Governors have made the environment a central issue. Money and effort has been pumped into solving many of the worst problems caused by short-term thinking in earlier decades.

Whilst the response of Government and industry in the early days, and to a large extent even today, was to seek better ways of managing and engineering the environment, the need for EE in schools only gradually became accepted. The Government has always been faced with the tension between maintaining economic growth, which is essential for improving the livelihood of 
the people, at the heart of which is free wheeling laissez-faire development, and maintaining environment quality which, in the long term, is just as essential to economic growth and quality of life. Recognition, however, has developed in Government that at the core of environmental protection is the hearts and minds of the public and of decision makers in particular. A White Paper 'Pollution in Hong Kong: A Time to Act' was published in 1989 and was a signal for change. It focused attention on environmental education. During the 1980s, responses to the challenge have come from the EPD itself, which funded the "One minute to midnight" education programme, from environmental pressure groups (such as WWF, Friends of the Earth and the Conservancy Association) and also, at this time, from the education authorities and schools.

\section{Environmental Education in Hong Kong Schools}

\section{The Education System}

Before describing the present state of Environmental Education in Hong Kong schools, it is first necessary to briefly outline the context of the education system in which curriculum development has taken place. Only then is it possible to understand the opportunities and constraints EE faces and the sort of teacher education that is needed. In the territory, there are nine years of compulsory education, six years of which is at primary level and three at secondary level. In practice, over $90 \%$ of young people stay on to Secondary 5 (grade 11 or age $16 / 17$ years). About $25 \%$ of students continue to Secondary 7 (grade 13), most of whom proceed to some form of advanced education either in one of Hong Kong's seven tertiary institutions or overseas. Hong Kong now has comprehensive education for all but this is a relatively recent phenomenon.

Administration of schools is mainly controlled by a small number of charitable foundations; a minority of schools are directly administered by government. In practice, 
however, the system is highly centralised. The education system reflects a compromise between Government's desire for uniformity of provision and maintenance of minimum standards, on the one hand, and a laissez-faire system as schools chose what subjects are to be studied, on the other. Government committees, comprising officials and invited educationalists, decide curricula which, whilst described as recommended, are in reality followed by all but the few international schools. Similarly texts to be adopted by schools have to be approved by central committees before they can be used. The centralised public examination system in particular is a major determinant of what is taught.

There is no core entitlement curriculum for schools in which one might have expected EE to have been present and schools have only recently started to move from highly academic programmes of study focusing on traditional school subjects in which the latter are typically highly discipline-oriented in character. Moreover many of the schools have been set up in the last decade and often seek to establish credibility through a focus on traditional school subjects. Socially relevant and cross-curricular subjects, such as EE, have often been viewed as largely peripheral. This, however, is starting to change following groundwork laid in the 1980s. Political change, social and environmental issues, the ramifications of universal lower secondary education and a new breed of young teacher are slowly encouraging educational reform and a broadening of the curriculum to meet wider expectations and needs. Acceptance of a need for an environmental component in the curriculum is a part of these reforms.

\section{The Environmental Curriculum}

The development of an environmental curriculum in Hong Kong has been long in gestation and slow in take up. Part of the reason for this lies in the context noted earlier but it is also because 
education, until recently, has largely been seen in terms of creating infrastructure for the economy; vocationalism has been a dominant force. Reforms in the 1960s and '70s were generally directed towards technology education. Environmental education was generally perceived at that time as a luxury and developments today have to accommodate these earlier views. Thus, whilst environment featured as a nominal key organizing concept in subjects such as the 1981 geography 16-19 syllabus and warranted a place in the biology, integrated science, social studies, junior geography and Economics and Public Affairs (EPA) syllabi, deep commitment to promoting an environmental ethic seemed rarely present in the schools. The emphasis instead centred on teaching about the environment. Little attention was given in practice to socially transformative education and to affective and conative aspects.

At the core of environmental education in Hong Kong for the 1990s are the Environmental Guidelines (Curriculum Development Committee 1992). These seek to set directions for environmental education and suggest ways in which it can be implemented in the school. The aims, which are expressed in a rhetoric that is open and ecocentric, are:

- $\quad$ to promote in pupils a lifelong and forward looking concern for the environment and to prepare them for making well informed, justifiable decisions regarding the conservation of environment so as to enable them to live as useful and responsible citizens.

The objectives of environmental education in schools similarly emphasise attitudinal and values development seek to help pupils to:

(a) appreciate and love nature;

(h) develop an ethic of respect and responsibility for the environment; 
(c) acquire knowledge and develop attitudes and skills that will enable them to participate in protecting and improving the environment;

(d) develop a lifelong commitment to environmental sustainability and protection;

(e) develop a holistic understanding of all aspects of environmental problems at local and global levels as a basis for solving them;

(f) form environmentally friendly behaviour and lifestyles that are conducive to the sound management of the environment; and

(g) realize that Hong Kong has a responsible role to play in the world community in solving regional and global environmental problems. (Curriculum Development Committee, 1992, pp.8-9)

Principles that are suggested to guide teachers in designing programmes in both the formal and informal curriculum throughout the school are consistent with accepted recommendations for EE today, namely that:

- $\quad$ learning should be experiential rather than instructional;

- $\quad$ a balanced viewpoint should be maintained for all issues;

- $\quad$ emphasis should be laid on the formation of attitudes; and

- $\quad$ individual contribution and participation should be encouraged.

(Curriculum Development Committee. 1992, pp.11-12)

The guidelines emphasised environmental education as a "whole school" concern. Schools are recommended to appoint an environmental co-ordinating committee to bring together environmental work across subjects and to arrange whole school events such as environment days, visits, etc. Whilst a cross-curricular approach was a central tenet of the guidelines, two separate programmes of environmental 
study have been proposed, one at Secondary 4-5 level (grade 10-11) and another at sixth form level (grade 12-13).

The grade 10-11 course was proposed in the late ' 80 s in response to a need for relevant programmes for non-academic pupils at the same time as Government was looking to establish the environment more definitively on the educational agenda. The curriculum took environmental elements from existing geography and biology syllabi in order to minimise resource problems. This was not a wise decision for the curriculum lacked coherence. However, the main problem was the initial decision that it would not be publicly examinable. This resulted in the syllabus being accorded low status in schools. As a consequence, there was a lack of interest from school principals and it was shelved. The ill-fated attempt was, however, indicative of EE thinking in the mid-'80s.

econd initiative took place at sixth form level in the '90s as part of a broadening of the grade 12-13 curriculum. A modular issues-based course of study requiring half the study-time of a traditional pre-university A level subject was proposed with Environmental Studies as one module. It centred on three issues: (i) implications for the future as humans continue to disrupt the world environment; (ii) the ways people are able to cope with the fact that the world's energy and natural resources are strictly limited and in danger of being exhausted; and (iii) what can be done to improve the Hong Kong environment in the face of population and industrial growth. The curriculum constituted a breakthrough in EE terms marking what Fien (1995) has described as the paradigm shift to a focus on a sustainable eco-future within an holistic inter-disciplinary framework. The programme emphasises the acquisition of thinking, study and presentation skills and a means whereby students can learn to harmonise the different approaches in the sciences and the humanities. This innovative course unfortunately has received only limited adoption with take-up by only about $10 \%$ of schools in the territory. The next few years will be critical for its future.

Given the fragility of the environment-specific curricula just described, cross-curricularity remains the main focus of environmental education in Hong Kong. The cross-curricular approach relies in part on 
individual subjects and the teachers of them taking up environmental responsibility. A number of the centrally designed subject curricula give recognition to environmental issues. Reference here can be made to the examination syllabi for Secondary 4-5 subjects (the Certificate of Education or CE curriculum for grades 10 and 11 school leavers) and that for Secondary 6-7 (the A level and AS level curriculum for grades 12 and 13 aged 17-19 years) (Hong Kong Examinations Authority, 1992a, 1992b). The power of public examinations in Hong Kong is such that these are crucial determinants of what is taught even outside of examination classes and provide good indicators of the general trend within education.

However, at CE level, some subjects contribute little if nothing to environmental education. Here one could target Maths, Chinese and English although teachers may use environmental topics as mediums for teaching. Some with obvious potential do not take up the challenge. For example, Engineering Science deals with refrigerants but not the problems caused by CFCs. Government and Public Affairs involves an analysis of Hong Kong policy areas but environment is not within the prescribed list. A 'whole-school approach' exists only in the rhetoric of official documents. In some subjects, environmental themes are set out in their curricula. Home Economics has a section entitled the "Healthy Environment" but takes a cleansing rather than sustainable perspective; the focus is technocentric rather than ecocentric. Biology does not directly include environmental awareness within its aims and objectives but contains topics on "Mans effect on his environment" highlighting aspects of pollution and conservation. In Chemistry, pollution problems associated with the combustion of fuels and pollution problems linked to detergents are discussed. Economics and Public Affairs (EPA) includes population growth, environmental pollution and environmental control within the context of how "major problems facing Hong Kong" are managed. Geography, however, probably makes the greatest contribution (Fung and Lee, 1990). A major section in the curriculum deals with "issues arising from man-land interaction and considers questions of over-population, energy resources and pollution", although again there is a concentration in the intended curriculum knowledge rather than the development of attitudes and encouraging changes in personal 
values and lifestyles; decisions whether the latter should be included are left to individual teachers.

A similar pattern is found at pre-university level. Perhaps indicative of changes to come, a new AS level Chemistry syllabus takes a stronger environmental line even if its older A level counterpart does not. The AS level has a prescribed section on "chemistry and the environment" and looks at the question of heavy metals, fertilisers, detergents and air pollution. A level Biology stresses environment in its aims in encouraging students to become responsible citizens in a changing world (aim 8) and to be able to recognise biological issues in environmental contexts (aim 7). The syllabus includes questions about resource exploitation, the effects of agriculture, atmospheric and water pollution and conservation. Geography again has a contribution although possibly not one as strong as at CE level and include topics on the environmental implications of agriculture, industry and urbanisation.

What comes over in the intended curriculum is an environmental education perspective with affective aims but detailed targets which are largely cognitive and reductionist. Central to the success of the initiatives are the teachers in the classroom and the curricular choices they make. Teachers as individuals need the understanding, skills and commitment to environmentalise their teaching. Without this, it is unlikely that programmes will be effective in producing environmentally literate pupils as intended in the guidelines. Consequently it is important to consider what effect the guidelines have in the schools and how teachers perceive them.

\section{Teacher attitudes and concerns}

Following the dissemination of the Environmental Guidelines in 1992, Fung and Lee (1993) surveyed 228 principals in about half of the secondary schools across Hong Kong. They looked at: (i) the status of environmental education in the formal curriculum of the school; (ii) the degree to which the guidelines have been discussed in school; (iii) environmental education activities, and (iv) the perceived assistance 
needed to improve and develop environmental education in the school. Further studies have been carried out more recently by Cheng (1994) and Lam (1995) with similar results.

Fung and Lee reported that the status of environmental education in schools was generally low. Only 7 (or 4.5\%) of the 155 respondents reported offering a distinctive environmental education programme and 14 (9\%) of schools indicated that they had no programme at all in the formal curriculum. The majority (68\%) incorporated environmental education into existing moral, civic or religious education class periods. The cross-curricular focus is clearly being interpreted in only a very narrow way. Incorporation across existing main-stream school subjects is generally not occurring. Lam (1995) found that most heads of geography departments did not see collaborating with other subject departments in developing EE as important and there is no reason to believe that the same is not true of teachers of other subjects. Follow-up interviews with 21 selected teachers showed that there was rarely an overall EE policy and in only one school a genuine cross-curricular approach. However, in Fung and Lee's investigation 84 (54\%) claimed that environmental education is systematically taught and it is interesting to note that these responses were mainly from newer schools reflecting, as suggested earlier, the way schools are coming to the new social realities of the '90s.

The low status of environmental education was parallelled by infrequent discussion of the Guidelines. Only 7 (4.5\%) of the school principals reported to Fung and Lee that they had both circulated and discussed the document with their staff; most of these principals were from long established church schools. Principals generally (76\%) just circulated the document although in $20 \%$ of schools even this had not occurred. For the most part, commitment and leadership seemed lacking although 65 of the schools had designated a teacher as an environmental coordinator and 35 had set up an environmental education committee. Most of these schools which had made formal arrangements, perhaps not surprisingly, were from the minority of government schools and, in contrast, nearly half of the schools in total who replied were not intending to follow the recommendations of the guidelines. 
Activities envisaged largely comprised visits to places such as nature reserves, the setting up of exhibitions and talks/video shows. On the other hand, visits to gardens, zoos, urban parks and factories, all of which are readily accessible in the urban area where most schools are located, were rarely suggested. Most activities emphasised the acquisition of knowledge about the environment; participatory, experiential activities were infrequent. Teachers seemingly lack the confidence and competence to adopt such approaches. This parallels findings of Wong and Stimpson (1994) who showed in a study 282 teachers that, whilst most started lessons in an open, participative, pupil centred way, they quickly reverted to a transmission mode as lessons progressed.

The problems perceived by teachers in Fung and Lee's and Lam's surveys were reflected in the types of assistance they sought. This included the need for teachers with EE expertise and teaching materials and for support from the community, parents and school management. The insecurity of teachers implied in the needs they highlighted express, as Tilbury (1993) has reported from UK student teachers, how little that teachers feel in control of the curriculum. Part of the problem in Hong Kong reflects the overburdening influence of the public examination system on what is taught. However, it also reflects the low level of personal empowerment and professional independence felt by the teachers.

The situation revealed was disappointing. One could argue that at the time of the Fung and Lee survey it was early days for the message being disseminated through the guidelines but one might also suggest this when it was likely to have most impact. Moreover it is probable that those teachers who replied in the surveys were more involved in curriculum development and hence the percentage of uptake may well not apply to the population as a whole. It is clear that much work is needed in respect of teacher education if effective implementation of the guidelines is to occur. The present strategy seems top-down in character and to have fallen into many of the traps highlighted by Fullan (1991) of making unwarrantable assumptions about teachers' knowledge and attitudes to change. Teachers seem to lack the necessary knowledge, confidence, commitment and desire to grasp the opportunities suggested. The clear lack of 
teacher readiness raises questions about the appropriateness of teacher education.

\section{Teacher Education for EE}

As noted earlier, teacher education is widely accepted as being crucial and curriculum initiatives will have little impact if teachers with responsibility in schools do fully understand the goals of EE and the sorts of learning experiences necessary. Teacher education needs to model EE in the schools. This section examines the state of affairs, firstly, in initial teacher education and, secondly, in continuing teacher education.

\section{Initial training}

Initial teacher education takes place in the Institute of Education, which was recently formed from the merger of four Colleges of Education, and in three of the seven Universities. The Institute prepares teachers for the primary-lower secondary sector whilst the universities focus mainly on the secondary sector. In general, however, there is a mismatch between the curriculum models practised within teacher education institutions and that needed for the sort of environmental education one would wish to see espoused in the schools, namely that EE should be open-ended, experiential, reflective and pupil centred.

The Institute of Education prepares non-graduate teachers in a Certificate in Education programme and is in the process of developing B.Ed. programmes. Its contribution to the process of preparing environmental educators is relatively small and is largely concentrated at an awareness raising level. Indicative of this is the way in which, for example, the Institute includes environment largely within a broad programme of Civic Education with an enrichment programme of talks, seminars, discussions, debates, video, etc. that embraces themes such as "Environmental Protection", "Environmental 
Revolution" and "Green life - how to produce a greener home and environment". Apart from this, trainee teachers can only develop their knowledge of EE through short optional courses. The emphasis is piecemeal centring on environmental orientation, knowledge acquisition and teaching techniques. Despite a rhetoric of reflection, a craft model dominates teacher training.

Post-Graduate Diplomas or Certificates in Education for graduate teacher are taken at the universities as either a pre-service course or a part-time evening programme in the early years of teaching. (The aim is phase out the latter but at present teacher shortages have not encouraged the implementation of such a policy.) Whilst, as in the Institute there is often a tendency towards narrow training, teacher education in the context of curriculum reform and development is a central tenet. None of the institutions involved, however, offers Environmental Education as a Major Curriculum subject in their PGD/PCEd programmes, there being no perceived demand from the schools for specialists in this area; only elective courses are offered. These use a cross-curricula perspective in support of the Guidelines for Environmental Education in Schools as described earlier. As in the Institute, the main aim is to help teachers become aware of how, in a practical sense, their main teaching subject can contribute. Similarly none of the present B.Ed degrees offered by the universities have a specialist EE B.Ed degree although there are modules within their programmes. One of the universities offers an environmental elective in its B.Ed. (Primary Education) and another has a compulsory environment module in its B.Ed (Social Science) degree. The programmes seek to enhance and build on serving teachers' existing understanding of the concept of environment and show how a multidisciplinary approach can be used to explain some of the major environmental problems facing Hong Kong. However, the teacher education model that is practised emphasises the application of learning theory. In both the Institute and the Universities, there is a need for a change in both outlook and approach. As Simpson et al. (1988) have commented about EE training elsewhere, "The task is more complex than putting environmental content into existing curricula" (p.17). 


\section{Continuing Teacher Education}

This mainly comprises either short courses or advanced courses at Masters level. The short courses are provided by: (i) the universities either directly through the Faculties of Education or in conjunction with their Extra-mural Departments; (ii) Government either through the Colleges of Education which they control or through the Inspectorate; and (iii) non-governmental environmental groups. For example, WWF adopted a curriculum development framework for teacher education and set up teacher work-shops to prepare teaching packs. With support from a number of charitable foundations and oil companies the materials were distributed free to all schools. The Universities have used a similar format to enhance teacher environmental understanding and develop materials to support the new AS level Environment module described earlier.

Opportunities exist for a small number of environmental educators to undertake Masters level study in Environmental Education either as a major specialism at the University of Hong Kong or as electives on a general M.Ed. at the Chinese University. The M.Ed in Environmental Education focuses on participants clarifying and developing their understanding of the idea of environment and of the concepts of environmental education, on the one hand, and curriculum development, implementation and evaluation on the other. It also provides an opportunity to update and enhance knowledge of environmental systems and issues through linkages with a parallel M.Sc. in Environmental Management. Reflection and selfdevelopment are key features of this programme for future leaders in EE.

\section{Implications}

As is found in other countries, Hong Kong suffers from an absence of mandated courses in environmental education for teachers. There is no legal requirement concerning the form and content of teacher education 
in the territory as there are, for example in the UK. However, this is not to argue for such provision or that such requirements necessarily produce teachers with the knowledge, skills and attitudes which are necessary for environmental education. Yet, at the same time, there is only limited pressure for change. Instead, there is a reliance on the enthusiasm of teacher educators both to provide programmes.

The nature of the teacher education institutions and the ethos within them have a marked influence on the degree to which environmental education training programmes achieve desired outcomes. The bureaucratic management style and the lack of inter-subject cooperation apparent in much of teacher education in particular in the former colleges of education works against the development of a suitable climate. This both affects and is affected by teacher educators beliefs about teacher preparation. In the territory, environmental education seems often to be the province of just a small group of committed teachers, yet Tilbury (1993) has gone so far as to claim that in the UK tutor influence is the core variable enabling, or constraining, curriculum development in environmental education. The lack of a cross-curricular perspective in teacher education in Hong Kong clearly does not help when attempts are being made to develop such a framework in schools. Robottom (1987) has argued in Australia that developing an EE perspective poses pedagogical challenges of teacher educators. This is also true in Hong Kong where interdiscipliniarity and investigation are frequently absent from programmes. Reflective pupils require reflective teachers.

Short inservice courses are put on as and when needed but of greater concern than the frequency of such courses is their style. The tendency is often to provide information rather than to facilitate teacher reflection. Expansion of teachers' own existing knowledge and beliefs about the environment through which they can come to understand how provision should be made for children is limited. The link with curriculum development and the professionalisation of teachers is an appropriate move in the right direction but needs strengthening. 


\section{Conclusion}

This review of environmental education in Hong Kong and the response of teacher education has attempted to show the present position in the territory and some of the problems that have to be faced. Hong Kong has been slow in developing programmes but in this it is perhaps not so dissimilar from other areas. However, environmental problems have now reached such a pitch that it is recognised that there is no time to lose. Winning the hearts and minds of the decision makers in this and the next generation is seen as a vital task. In a "can-do" society such as Hong Kong, once a problem is accepted, it is usually quickly addressed. This is happening in the case of environmental education in schools and, to a lesser extent, with the training of the teachers who will carry out the job. The danger is that, in the rush to solve what is certainly a pressing problem, curricular initiatives and teacher education will become instrumental and mechanistic rather than focusing on reflection, self-clarification and deep learning.

There is a need for a positive effort to involve teachers and teacher education programmes in environmental awareness initiatives. The rhetoric of schools and teacher education institutions generally espouse social relevance and links with the world of the student; practice is generally different. NGOs, such as FOE, have recently been involved in successful community campaigns on housing estates in Hong Kong to conserve energy and have acted as facilitators for local action. Perhaps similar approaches should be adopted needed in schools and teacher training establishments. A culture is required which sees the environment as a priority; only then will EE be effective.

\section{REFERENCES}

Cheng, W.M. (1994) The implementation of environmental education through the teaching of S4-S5 
biology, geography and history in Hong Kong secondary schools, unpublished masters dissertation, Faculty of Education, The University of Hong Kong.

Curriculum Development Committee (1992) Guidelines on environmental education in schools (Hong Kong, The Education Department).

Hong Kong Examinations Authority (1992a) Hong Kong Certificate of Education examination regulations and syllabuses (Hong Kong, Hong Kong Examinations Authority).

Hong Kong Examinations Authority (1992b) Hong Kong Advanced Level examination regulations and syllabuses (Hong Kong, Hong Kong Examinations Authority).

Environmental Protection Department (1994) Environment Hong Kong: a review of 1993 (Hong Kong, The Environmental Protection Department).

Fullan, M.G. (1991) The meaning of educational change (New York, The Teachers College Press).

Fung, Y.W. and Lee, J. (1990) A comparative study of geography curricula in Hong Kong and China with reference to their contribution to environmental education, in Stimpson, P.G. and Kwan, Y.L.

(Eds.) Teaching geography in and about Asia-Pacific countries (Hong Kong, IGU Commission on Geographical Education/The University of Hong Kong).

Fung, Y.W. and Lee, J. (1993) Environmental education in Hong Kong secondary schools, in Final Report of the UNESCO Asia-Pacific Regional Experts Meeting on Overcoming the Barriers to Evnvironmental Education through Teacher Education, (Brisbane, Australian Association for Environmental Education)

Lam, K.K. (1995) A study of the concerns and practices of heads of geography departments in the implementation of EE in secondary schools in Hong Kong, unpublished masters dissertation, Faculty of Education, The University of Hong Kong.

O'Riorden, T. (1989) The challenge for environmentalism, in Peet R. and Thrift, N. (Eds.) New Models in Geography, Volume 1 (London, Unwin Hyman). 
Robottom, I. (1987) The dual challenge for professional development in environmental education, in Greenall, A. (Ed.) Environmental Education- Past, Present and Future. Proceedings of the Third Natural Environmental Education Seminar and Workshop, AGPS, Canberra, p.72-83.

Simpson, P., Hungerford, H. and Volk, T. (1988) Environmental Education: A Process for Pre-service Teacher Training Curriculum Development. IEEP Environmental Education Series No.26 (UNESCO-UNEP, Paris)

Stimpson, P.G. (1985) Country Parks in Hong Kong: A consequence of socio-economic necessity, Landscape Research, 10(3), pp. 21-25.

Tilbury, D. (1992) Environmental education within pre-service teacher education: The priorities of priorities, International Journal of Environmental Education and Information, 11(4), pp. 267-280.

Tilbury, D (1993) A grounded theory of curriculum development and change in environmental education at the teacher education level, Proceedings of the UNESCO Asia-Pacific Region International Experts Meeting, Griffith University, Australia, 4-9 July 1993.

UNESCO (1980) Environmental Education in the light of the Tbilisi Conference, (Paris, UNESCO).

Wilkie, R. (1985) Mandating pre-service environmental education teacher training: The Wisconsin experience, Journal of Environmental Education, 17(1), pp.1-18.

Wong, E.M.O. and Stimpson, P.G. (1994) Teaching styles of Hong Kong's environmental educators in secondary schools, Research in Education, 52, pp.1-12. 


\section{Notes on Contributor}

PHILIP STIMPSON is a Senior Lecturer in the Department of Curriculum Studies at the University of Hong Kong where he is the Director of the M.Ed. programme in Environmental Education and is engaged in a number of research projects on curriculum implementation and children's learning in EE. He is a author in the UNESCO project on Innovations in Teacher Education through Environmental Education in the Asia-Pacific region. He has published in the areas of environmental and geographical education. Correspondence: Department of Curriculum Studies, The University of Hong Kong, Pokfulam, Hong Kong. E-mail: HRASPGS@hkucc.hku.hk 